\title{
Estimating the Reliability and Uncertainty of Coordinate Measuring Machines by Numerical Method

\author{
Sompoap Talabgaew
}

\begin{abstract}
This research develops an alternative approach for the prediction of uncertainty of multi axis machines, Coordinate Measuring Machine (CMM), by using geometric error information in each axis or repeatedly measured coordinates. It also introduces a procedure to calculate the probability of accepting a measured position within a specified range. The developed model has resulted in an improvement in the probability of accepting a measured position, compared to previously published models and results.

Keywords: Reliability, Uncertainty, CMM
\end{abstract}

\section{Introduction}

Currently, the automated machine is widely used in modern manufacturing. CMM or Coordinate Measuring Machine plays a crucial role for measuring the complicated workpiece shape or high accurate and precise shape, especially, mold making, sheet metal forming or automotive machining. Theoretically, the CMM moves its probe head to measure the workpiece from point to point and then the computer software will simultaneously process to estimate the "best fit" for these points as shown in Fig. 1.

The reliability of CMM may be defined as its uncertainty. It is the ability to perform its measurement function effectively under specified operating condition [3,4]. Clearly, all measured positions from CMM operation might have been affected by their measurement uncertainty [13] because while moving, there are many noise factors affecting CMMs' probe head so that probe position at the workpiece surface may deviate from target position. The uncertainty of CMM can be explained as the interval in which $95 \%$ of the measured values are placed [14].

\section{CMM Uncertainty}

There are many possible causes leading to CMM uncertainty as shown in Fig. 2 [8]. However, the most significant factors affecting CMM uncertainty can be classified into 2 types that are systematic error and random error $[11,13]$.

\section{Sompoap Talabgaew}

King Mongkut's University of Technology North Bangkok Thailand

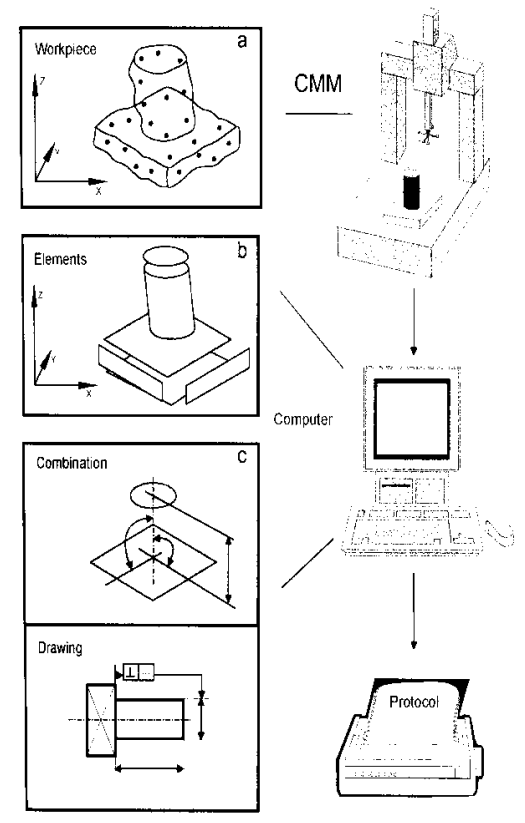

Figure 1. Nature of coordinate metrology [7]

\subsection{Systematic error}

This error is mainly caused by geometric error around $60 \%-70 \%$ of total error as shown in Fig. 3 [2]. The geometric error will directly result to measurement error because the difference system between workpiece

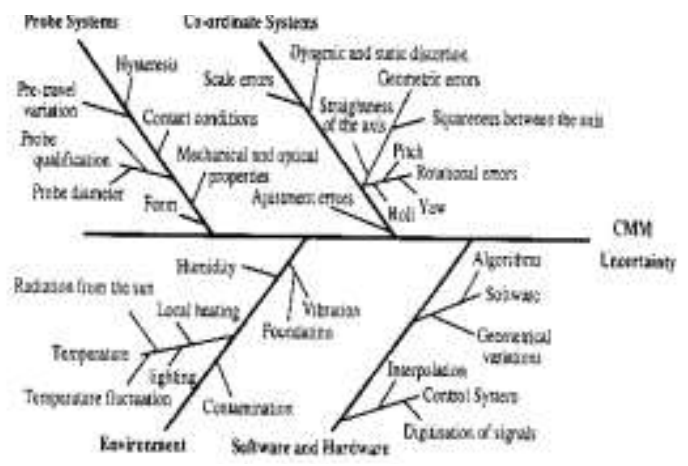

Figure 2. All possible factors affecting to CMM uncertainty 


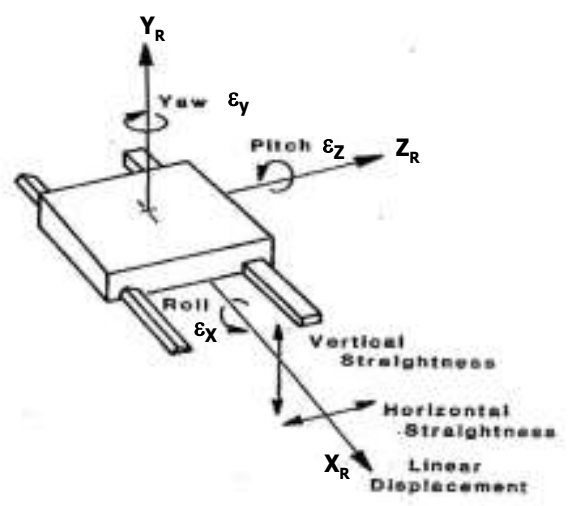

Figure 3. The geometric error of machine structure

\subsection{Random error}

Random errors vary under operating conditions, for example the environmental conditions, the skill of operators, or CMM itself, etc. It is roughly said that the total errors (both systematic and random errors) can be taken into consideration as random error because of the lack of specific knowledge of the existing errors and where they come from and are assumingly treated as randomly independent.

\section{The reliability of $\mathrm{CMM}$}

As known, the main purpose of CMM has been used for complex dimension measurement e.g. surface, pitch centered diameter (PCD) and what industry highly expects from CMM is its accuracy and precision. Since the bias (systematic error) of a CMM can be calibrated, the only remaining error is that due to uncertainty as seen in Fig. 4.

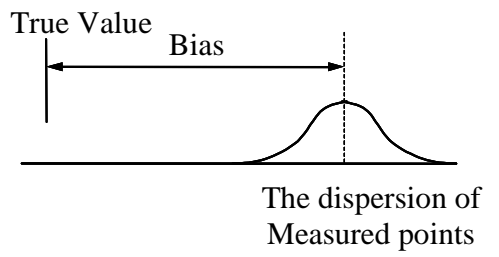

Figure 4. Bias and uncertainty [1]

As known, uncertainty can arise from various sources as shown in Fig.2. While a CMM is performing the measurement, there are many factors causing error at the probe position. Theoretically, when probe head touches the target position on the workpiece surface, the probe position at target position (in 2 or 3 -dimension) is translated to be a reading position that is ideally assumed to be as same coordinate as the true coordinate in part drawing. However, in reality, while probe head is moving, there are many noise factors e.g. probe systems, coordinate systems, environments and software \& hardware affecting its performing, by this reason, probe position at the workpiece surface may deviate from target position (see Fig. 5). The larger error of measured position, the worse accurate and precise of CMM.

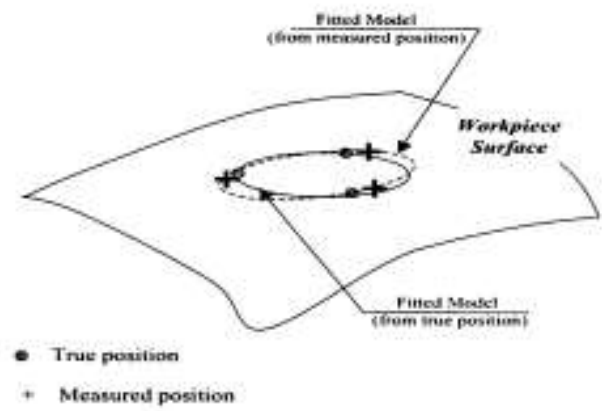

Figure 5. The measure positions including error could be leading to the wrong substituted geometry

Theoretically, the reliability of CMM could also be considered as the ability to repeat measurement during the period of time or, on the other hand, explained as the interval in which $95 \%$ of the measured values are placed in this interval [10]. For example, if a CMM repeatedly measures and there are at least $95 \%$ of all measured values lie within a tolerance zone of measurement specification. It can be said that this CMM has high reliability. Fig. 6 represents the outline of this relationship.

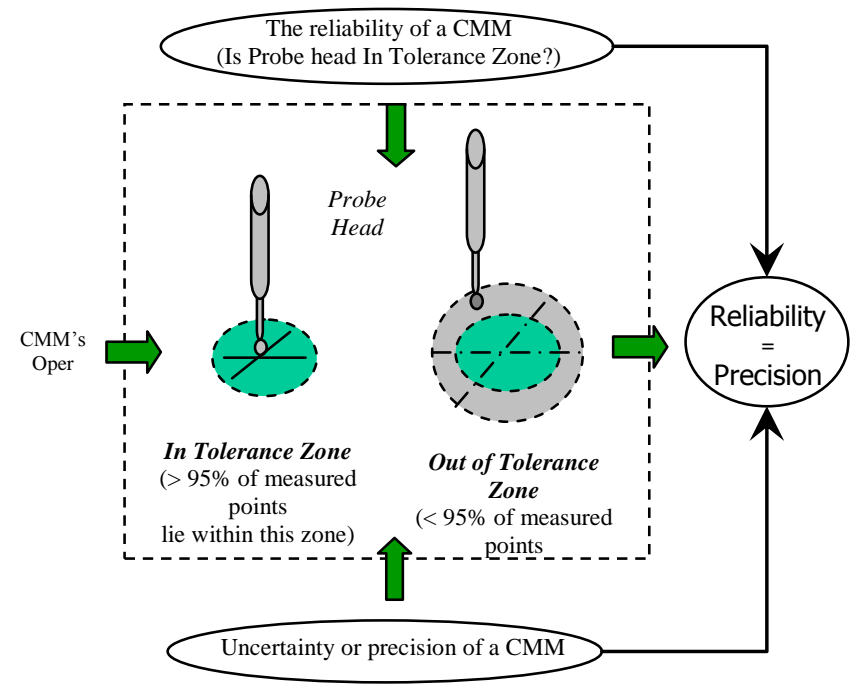

Figure 6. A relationship between the reliability and uncertainty of CMM

\section{Uncertainty ellipse}

As mentioned previously, there is the random error in the coordinates of each point within the measuring volume of the CMM. Hence, each point in the measuring volume can be viewed as having a "random errors cloud" associated with it. In general, firstly, these random error clouds will not be spherical because the uncertainty sources are associated with a particular axis of the CMM, 
which elongates the cloud along that direction [14]. The random errors cloud could be viewed as ellipsoid, as shown in Fig. 7 and 5 [5,6]. Secondly, the uncertainty of the measured coordinate $(x, y, z)$ is statistically independent and distributed in a Gaussian. The set is an ellipse overlap with the coordinate $(\mathrm{x}, \mathrm{y}, \mathrm{z})$.

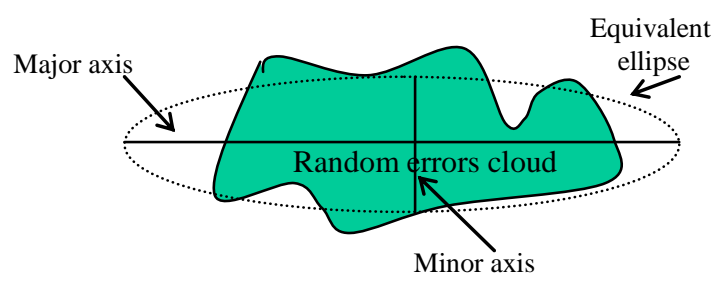

Figure 7. Equivalent ellipse for a random errors cloud

The random errors can be considered as uncertainty of measurement. When the probe is moved to the destination, there will be the difference between the true position and the measured position. If a specific position is measured over and over (repeatability), the random space will be as ellipsoid with which the major axis will be parallel to the axis that is moving (see Fig. 8). So the random error is similar to the uncertainty and is also likely presented in the most mechanically accurate CMMs. The most commonly applied method of uncertainty evaluation is the Guide to the Expression of Uncertainty in Measurement (GUM) [3].

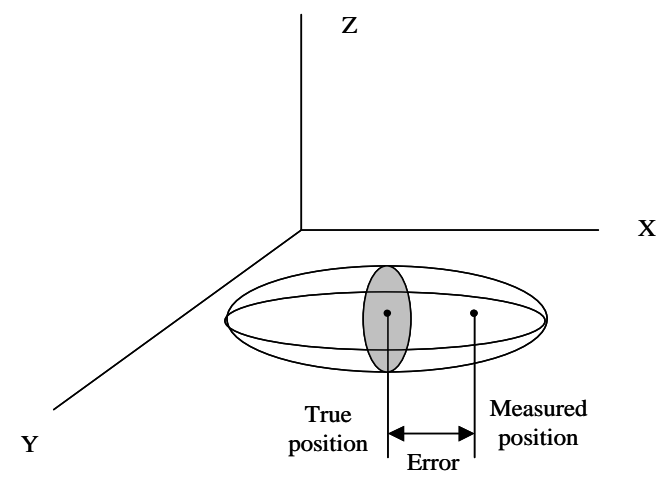

Figure 8 . The three-dimensional random error in the coordinates

\section{Reliability Model for Probability of Accepting Measured Positions}

Assuming that a measured point $(\mathrm{P})$ on the workpiece surface can be treated as random position, therefore, the $\mathrm{x}$, $\mathrm{y}$ coordinates can also be considered the random variables. It is assumed that uncertainty is normally distributed around the nominal value of the position. The CMM's reliability model can be expressed by the probability of a randomly measured position $\mathrm{P}(\mathrm{x}, \mathrm{y})$ within an allowable zone of uncertainty $(\mathrm{Au})$. The double integral for joint probability density is to find the area under the curve or probability itself [9].
$\operatorname{Pr}(u)=$ Probability that a measured position lies within an allowable zone of uncertainty $\left(\mathrm{A}_{\mathrm{u}}\right)$

$$
\operatorname{Pr}(u)=\iint_{A_{U}} f(x, y) d x d y
$$

where,

$f(x, y)$ is bivariate normal joint probability density function of random measured position variables $(\mathrm{x}, \mathrm{y})$, in which $\mathrm{x} \sim$ $\mathrm{N}\left(0, \sigma_{x}^{2}\right), \mathrm{y} \sim \mathrm{N}\left(0, \sigma_{y}^{2}\right)$ and no correlation coefficient exists between two axial errors ( $\mathrm{x}$ and $\mathrm{y}$ ).

The bivariate probability density function is given by:

$$
f(x, y)=\frac{1}{2 \pi \sigma_{\delta x} \sigma_{\delta y}} \exp \left[-\frac{1}{2}\left(\frac{x^{2}}{\sigma_{\delta x}^{2}}+\frac{y^{2}}{\sigma_{\delta y}^{2}}\right)\right]
$$

where,

$\sigma_{\delta x}$ is the standard deviation of error in $\mathrm{x}$ - axis

$\sigma_{\delta y}$ is the standard deviation of error in $\mathrm{y}-$ axis

Fig. 9 shows a contour of the bivariate probability density function (solid line) that lies on uncertainty zone (dash line) that is the probability of accepting a measured position (shade area).

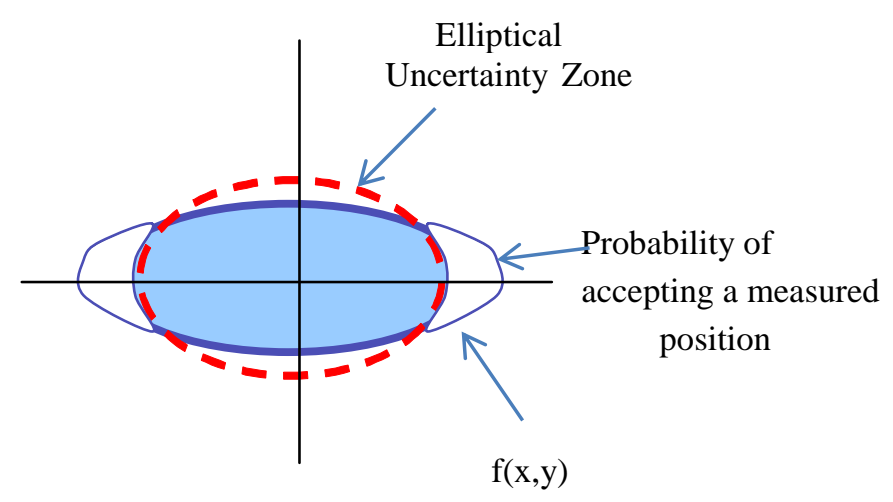

Figure 9 . The probability of accepting a measured position $\mathrm{P}(\mathrm{x}, \mathrm{y})$ lies within an elliptical uncertainty $(\mathrm{Au})$

The probability that the measured position $\mathrm{P}(\mathrm{x}, \mathrm{y})$ lies within an allowable area of uncertainty zone $(\mathrm{Au})$ is, as shown in Figure 7, given by

$\operatorname{Pr}(\mathrm{u})=\iint_{\mathrm{A}_{\mathrm{C}}} \frac{1}{2 \pi \sigma_{\delta \mathrm{x}} \sigma_{\delta \mathrm{y}}} \exp \left\{-\frac{1}{2}\left[\frac{\mathrm{x}^{2}}{\sigma_{\delta \mathrm{x}}^{2}}+\frac{\mathrm{y}^{2}}{\sigma_{\delta \mathrm{y}}^{2}}\right]\right\} \mathrm{dxdy}$

Substituted

$$
\begin{aligned}
& \lambda=\frac{R}{\sigma_{\delta x}}=\frac{\sqrt{x^{2}+y^{2}}}{\sigma_{\delta x}}, u=\frac{\sigma_{\delta y}}{\sigma_{\delta x}}, x=R \cos \theta, \\
& y=R \sin \theta, d x d y=R d R d \theta, \quad S(\theta, u)=\cos ^{2} \theta+\frac{\sin ^{2} \theta}{u^{2}}
\end{aligned}
$$


Proc. of The Third Intl. Conf. On Advances in Civil, Structural and Mechanical Engineering - ACSM 2015

Copyright (C) Institute of Research Engineers and Doctors, USA .All rights reserved.

ISBN: 978-1-63248-083-5 doi: 10.15224/ 978-1-63248-083-5-67

The equation (3) can be transformed from Cartesian to be Polar coordinates and expressed as follows;

$$
\frac{1}{2 \pi \mathrm{u}} \int_{0}^{2 \pi\left(\mathrm{R} / \sigma_{\delta \mathrm{x}}\right)} \int_{0}^{\left\{-\frac{\lambda^{2}}{2}[\mathrm{~S}(\theta, \mathrm{u})]\right\}} \lambda \mathrm{d} \lambda \mathrm{d} \theta
$$

$$
=\frac{1}{2 \pi \mathrm{u}} \int_{0}^{2 \pi} \frac{\left\{1-\mathrm{e}^{-\frac{\mathrm{S}(\theta, \mathrm{u})}{2}\left(\mathrm{R} / \sigma_{\delta \mathrm{x}}\right)^{2}}\right\}}{\mathrm{S}(\theta, \mathrm{u})} \mathrm{d} \theta
$$

"Composite Trapezoidal Rule" is applied to solve Equation (5.4) by numerical method as follows;

$I=\frac{h}{2}\left[f\left(x_{0}\right)+f\left(x_{n}\right)+2 \sum_{i=1}^{n-1} f\left(x_{i}\right)\right]$

and "Simpson's Rule"

$I=\frac{h}{3}\left[f\left(x_{0}\right)+f\left(x_{n}\right)+2 \sum_{i=2}^{2 n-2} f\left(x_{i}\right)+4 \sum_{i=1}^{2 n-1} f\left(x_{i}\right)\right]$

where; $\mathrm{b}=2 \pi, \mathrm{a}=0, \mathrm{n}=1000$ and $h=\frac{b-a}{n}$

\section{Comparing the models}

The developed model in this paper has been compared with the model done in previous research. Those who performed the research in this area are well known such as Shin and Wei [12]. The parameters used to calculate the probability of accepting a measured position $\mathrm{P}(\mathrm{x}, \mathrm{y})$ that lies within an elliptical uncertainty $(\mathrm{Au})$ are:

- the standard deviation of error in $\mathrm{x}-$ axis $\left(\sigma_{\delta x}\right)=$ $0.11825 \mathrm{~mm}$.

- the standard deviation of error in $\mathrm{y}-$ axis $\left(\sigma_{\delta y}\right)=$ $0.10549 \mathrm{~mm}$.

- the radius of tolerance zone $(R)$ from $0.02 \mathrm{~mm}$. to 0.40 $\mathrm{mm}$

Comparing the developed model solved by Trapezoidal and Simpson's rule with Shin \& Wei model, finally, the results of probability of accepting a measured position are shown in Table 1 and Figure 10.
TABLE 1: Comparing the probability of accepting a measured position with the tolerance zone between the developed model and Shin \& Wei model

\begin{tabular}{cccc}
\hline $\begin{array}{c}\text { Radius of } \\
\text { Tolerance } \\
\text { Zone }(\mathrm{mm})\end{array}$ & $\begin{array}{c}\text { Shin \& } \\
\text { Wei } \\
(1992)\end{array}$ & $\begin{array}{c}\text { Trapezoidal } \\
\text { Rule }\end{array}$ & $\begin{array}{c}\text { Simpson } \\
\text { Rule }\end{array}$ \\
\hline 0.02 & 0.0159 & 0.0159 & 0.0159 \\
0.04 & 0.0621 & 0.0621 & 0.062 \\
0.06 & 0.1343 & 0.1343 & 0.1341 \\
0.08 & 0.2261 & 0.2261 & 0.2258 \\
0.10 & 0.3299 & 0.3299 & 0.3294 \\
0.12 & 0.4379 & 0.4379 & 0.4373 \\
0.14 & 0.5432 & 0.5432 & 0.5425 \\
0.16 & 0.6404 & 0.6404 & 0.6395 \\
0.18 & 0.7256 & 0.7256 & 0.7246 \\
0.20 & 0.7971 & 0.7971 & 0.796 \\
0.22 & 0.8545 & 0.8545 & 0.8534 \\
0.24 & 0.8989 & 0.8989 & 0.8977 \\
0.26 & 0.9318 & 0.9318 & 0.9306 \\
0.28 & 0.9554 & 0.9554 & 0.9542 \\
0.30 & 0.9717 & 0.9717 & 0.9704 \\
0.32 & 0.9826 & 0.9826 & 0.9813 \\
0.34 & 0.9896 & 0.9896 & 0.9883 \\
0.36 & 0.9940 & 0.9940 & 0.9926 \\
0.38 & 0.9966 & 0.9966 & 0.9953 \\
0.40 & 0.9981 & 0.9981 & 0.9968 \\
\hline & & &
\end{tabular}

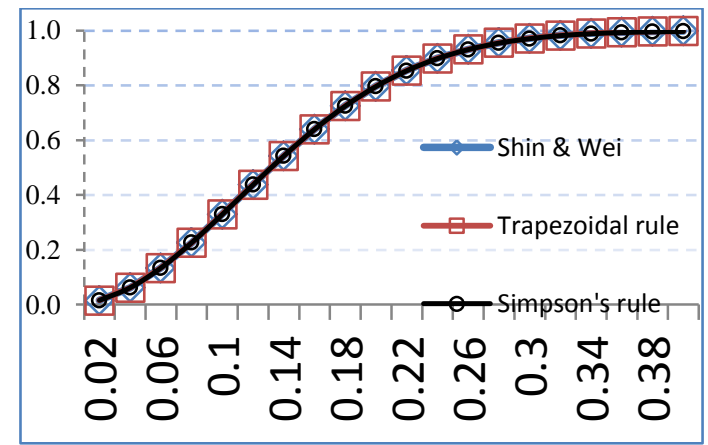

Figure 10. Graphical comparison of the probability of accepting a measured position with the tolerance zone between the developed model and Shin \& Wei model

From Table 1 at the same radius of tolerance zone, the probability of accepting a measured position calculated by numerical method is nearly closed to those reported by Shin \& Wei.

\section{Conclusion}

Several methods can be employed to assess the reliability or uncertainty of CMM. Presently, using laser interferometer, ball bar, and artifacts for calibrating and enhancing the performance have received wide acceptance in the research community dealing with performance 
evaluation of CMM. Although these methods are very effective, they are too costly and time consuming to make them implementable on the shop floor.

The research work presented here is an extension to these recent research efforts. It has utilized the concept of measurement uncertainty in CMM to provide a faster and less expensive approach to assess the CMM performance. The developed models resulted in an improved probability of accepting measurements.

\section{References}

[1] Automotive Industry Action Group, "Measurement Systems Analysis", Reference Manual, Second Edition, MI, (1995)

[2] Barakat, N. A., Spence, A.D. and Elbestawi, M.A., "Adaptive Compensation of Quasi-Static Errors for an Intrinsic Machine", International Journal of Machine Tools and Manufacturing, Vol. 40, pp. $2267-2291(2000)$

[3] Drescher, J. D., "Assessment of Machine Tool Accuracy Using ISO-Guide to The Expression of Uncerainty in Measurement (GUM)", American Society For Precision Engineering”, Vol. 16, pp. 6164, (1997)

[4] Elshennawy, A. K. and Ham, I. (1990),"Performance Improvement in Coordinate Measuring Machines by Error Compensation", Journal of Manufacturing Systems, 9, 151-158

[5] Hulting, F. L., "Method for Analysis of Coordinate Measurement Data", Computing Science and Statistics, Vol. 24, pp. 160-169, (1992)

[6] Liu, Z. Q., "Repetitive Measurement and Compensation to Improve Workpiece Machining Accuracy", International Journal Advance Manufacturing Technology, Vol. 15, pp. 85-89, (1999)

[7] Ni, J. and Lee, J., "Coordinate Measuring Machines", Coordinate Measuring Machines and Systems, Edited by Bosch, J. A., Marcel Dekker, Inc., NY. Pp.39 - 74 (1995)

[8] Phillips, S. D., Borchardt, B., Sawyer, D., Estler, W. T., Ward, D., Eberhardt, K., Levenson, M. S., McClain, M., Melvin, B., Hopp, T. and Shen, Y., "The Calculation of CMM Measurement Uncertainty via The Method of Simulation by Constraints",
American Society For Precision Engineering, Vol. 16, pp. 443-446, (1997)

[9] Rabinovich, S. G., "Measurement Errors and Uncertainties: Theory and Practice", Translated by Alferieff, M. E., Second edition, AIP Press, NY, (2000)

[10] Salomons, O. W., Jonge Poerink, H. J., Van Slooten, F., Van Houten, F. J. A. M. and Kals, H. J. J., "A Tolerancing Tool Based on Kinematic Analogies", Computer-Aided Tolerancing, Edited by Kimura, F., Chapman \& Hall, NY, pp. 47-70, (1995)

[11] Shen, Y and Duffie, N. A., "An Uncertainty Analysis Method for Coordinate Referencing in Manufacturing Systems", Transactions of the ASME, Vol. 117, February, pp. 42-48, (1995)

[12] Shin, Y.C. and Wei, Y., "A Statistical Analysis of Positional Errors of a Multiaxis Machine Tool", Precision Engineering, Vol. 14, No. 3, pp. 139 - 146 (1992)

[13] Takatsuji, T., Osawa, S. and Kurosawa, T., "Uncertainty Analysis of Calibration of Geometric Gauges", Journal of the International Societies for Precision Engineering and Nanotechnology, Vol. 26, pp. 24-29, (2001)

[14] Weckenmann, A. and Rinnagl, M. "Acceptance of Processes: Do We Need Decision Rules?", Precision Engineering, Vol. 24, No. 3, pp. 264-269, July, (2000)

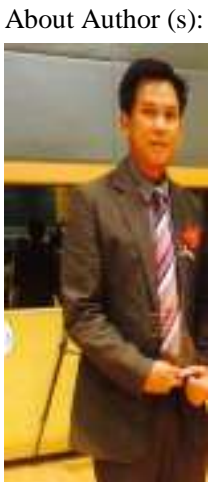

Sompoap Talabgaew is an assistant professor in the department of teacher training in mechanical engineering at King Mongkut's University of Technology North Bangkok, Thailand. He received $\mathrm{Ph} . \mathrm{D}$. in Industrial Engineering from University of Central Florida, US and $\mathrm{He}$ has specialized in reliability and maintenance engineering for power plant and petrochemical plant in Thailand. 